\title{
VITALIDADE URBANA NOS ESPAÇOS PÚBLICOS: UM ESTUDO NA CIDADE DO PORTO, PORTUGAL
}

\section{URBAN VITALITY IN PUBLIC SPACES: A STUDY IN THE CITY OF PORTO, PORTUGAL}

\author{
Trícia Caroline da Silva Santana \\ Graça Correia Ragazzi
}

\section{RESUMO}

Este artigo se propôs a analisar a relação entre a morfologia espacial e a percepção dos usuários. O intuito foi compreender quais aspectos indicados pela literatura são percebidos pelos usuários e como isso influencia a vitalidade de um espaço público. O estudo de caso usou mapeamentos comportamentais centrados no lugar, levantamentos físicos in loco, e registros fotográficos. Os resultados mostraram que espaços para se sentar, o estado de conservação e manutenção, a presença de arborização e paisagismo, a estética do lugar, e as características de uso do solo do entorno são percebidos pelos usuários e se refletem nas maneiras de utilização do lugar. Considera-se que, embora os elementos projetuais e a combinação desses seja um potencializador nos usos, a percepção que as pessoas têm do espaço e do entorno em que ele se encontra deve ser tomada como referencial na proposição dos espaços públicos.

Palavras-chave: Jardim. Percepção. Morfologia Urbana. Espaço Público.

\section{ABstract}

This article aims to analyze the relationship between the spatial morphology and the perception of the users. The intention was to understand, what aspects indicated by the literature are perceived by the users and how this influences the vitality of a public space. The case study included the use of site-based behavioral mapping, in-place physical surveys, as well as photographic records. The results showed that spaces to sit, the state of conservation and maintenance, the presence of afforestation and landscaping, the aesthetics of the place, besides the characteristics of the use of the surrounding soil, are perceived by the users and are reflected in the ways of using the place. It is considered that, although the design elements and the combination of these are a potentiator in the uses, people's perception of the space and the environment in which it is found must be taken as a reference in the proposition of public spaces.

Keywords: Garden. Perception. Urban Morphology. Public Space. 


\section{INTRODUÇÃO}

A temática trabalhada neste artigo é a vitalidade urbana, assunto de grande importância atualmente, cujas nuances podem ser discutidas a partir de referenciais derivados de campos do conhecimento, como Geografia, Filosofia, Sociologia e Psicologia, entre outros. Na base da discussão encontram-se dois temas importantes para entender a vida na cidade contemporânea: (1) a chamada "crise dos espaços públicos", que denuncia o acentuado esvaziamento dos locais de convívio coletivo na cidade; (2) o atual debate sobre elementos que promovem a ocupação do espaço público, o qual, em contraponto à ideia anterior, volta-se para a ampliação desse uso. Longe de serem antagônicas, tais ideias se complementam, sendo importante entendê-las conjuntamente, como será comentado brevemente a seguir.

O senso comum e a literatura especializada, como Arendt (1991), Habermas (1984), Jacobs (2001) e Sennet (1988), entre outros, apontam que, a partir da segunda metade do século XX, assistimos ao colapso da vida coletiva no contexto público, relegando importantes estruturas urbanas ao desuso. Em consequência, muitas práticas sociais que eram características desses espaços foram direcionadas a locais que favorecem maior permanência do usuário por ofertarem mais conforto e segurança, como condomínios fechados, clubes exclusivos, shopping centers e parques temáticos. Ou seja, quanto maiores as possibilidades de vida coletiva e recreativa em âmbito privado, maiores as possibilidades de desvalorização dos espaços públicos. Nesse sentido, Caldeira (2000) comenta que os chamados "enclaves fortificados" direcionados ao consumo, lazer, trabalho, moradia e entretenimento das classes média e alta (como condomínios fechados, shopping centers, centros empresariais, clubes) estão mudando a paisagem das cidades, suas normas de segregação espacial, a natureza de seus espaços públicos e a interação entre diversos estratos sociais. Confirmando essa condição, autores como Gomes (2002) e Gehl (2006) argumentam que a busca por segurança faz com que atualmente vivenciemos mudanças na utilização dos espaços livres públicos, acarretando o declínio no seu uso enquanto local de permanência, lazer, recreação e sociabilidade.
Em vez de se debruçarem sobre a crise, outros autores dedicamse a fazer emergir o debate sobre a vitalidade dos espaços públicos, voltando-se para os locais onde ela é encontrada e para o entendimento das condições que favorecem vivências públicas coletivas harmoniosas. Nesse sentido, Gehl e Gemzøe (2002) argumentam que parte do desuso está ligada ao empobrecimento dos projetos dos espaços públicos, que não acompanham as mudanças sociais. Além disso, os autores discorrem sobre fatores que precisam ser trabalhados a fim de que estes ambientes sejam capazes de acolher a vida social coletiva, entre os quais salientase a importância de restringir o trânsito de veículos e priorizar a ocupação dos espaços pelos pedestres.

Voltando-se especificamente para o projeto dos espaços públicos, Yurgel (1983, p. 18) destaca os danos ocasionados pela adoção de uma abordagem funcionalista pelos planejadores, que muitas vezes "minimizam a importância do lazer como parte das políticas públicas e dos programas de necessidades das intervenções", relegando-o ao aproveitamento de espaços ociosos. Nesse sentido, a autora enfatiza a necessidade do profissional: (1) entender o lazer e a recreação como atividades essenciais ao bem-estar e ao desenvolvimento humano; (2) compreender o espaço público como lócus privilegiado desse lazer, elevando seu planejamento a item essencial na política urbana.

Em uma espécie de analogia à vitalidade humana, a vitalidade de um espaço foi entendida como elemento indispensável à saúde e à vida da cidade, como uma linha intermediária entre a apatia e a excitação. Trata-se, portanto, da capacidade de animação em função das relações sociais que acontecem em um lugar, sendo condicionada pelos atributos morfológicos do ambiente, mas também pela percepção que seus usuários têm dele. Supõese, assim, que exista um tipo de vitalidade desejável para cada tipo de espaço, isso é, que uma área comercial exige um tipo de animação diferente daquela necessária a um setor residencial, embora alguns dos elementos/atributos dessa vitalidade possam ser válidos para ambos.

Embora a possibilidade de haver uma relação direta entre as características físicas dos espaços livres públicos e sua vitalidade 
seja atraente, ela também tem sofrido críticas, sobretudo relacionadas a tratar-se de uma ideia tanto simplista quanto determinista, que desconsidera a complexidade e a multiplicidade de aspectos que influenciam a dinâmica urbana (HOLANDA, 2011; NETTO, 2006).

Complementando as várias abordagens que discutem a utilização dos espaços públicos e a promoção da vitalidade (análise morfológica, sociológica, são alguns exemplos), têm-se os estudos voltados para a percepção ambiental que evidenciam que a compreensão acerca do funcionamento de um local passa, necessariamente, pelo entendimento do modo como seus usuários o percebem. Sob essa perspectiva, autores como Tuan (1983) e Hall (1977) esclarecem que a percepção de um ambiente estabelece diferentes modos das pessoas entendê-lo e vivenciá-lo. Para tanto, as informações advindas dos sentidos (visão, audição, tato, olfato, cinestesia) e a detecção (pelo usuário) da receptividade à sua presença produzem percepções diferenciadas do local, afetando as relações desse indivíduo nele e com ele. Além disso, a percepção também seria influenciada pela memória (individual e coletiva) relacionada ao local, outro aspecto a ser considerado para a adequada compreensão de um lugar (JODELET, 2005).

Articulando essa argumentação e considerando que a vitalidade de espaços livres públicos pode ser compreendida a partir de sua morfologia e da percepção de seus usuários, intenta-se compreender que elementos indicados pela literatura são percebidos pelos usuários, no que tange à vitalidade urbana.

\section{Os elementos das Vitalidade uRbana nos ESPAÇOS LIVRES PÚBLICOS}

Para discutir o Jardim Carrilho Videira como objeto empírico deste artigo, deve-se levar em conta o entendimento como parte de um conjunto mais amplo, como seja, o sistema de espaços livres da cidade, o que implica atenção para sua espacialidade (aspectos paisagísticos, morfológicos e funcionais), para o contexto em que está inserido e para sua conotação como um dos agentes das relações sociais na urbe.
Partindo-se dessa premissa, torna-se essencial entender o que é um sistema de espaços livres para, mais adiante, discorrer sobre o conceito de praça, ponto central deste artigo. A noção de sistema está pautada na reunião de elementos que são partes de um todo maior (componentes) e que se inter-relacionam (ou interagem) entre si, cada qual assumindo sua própria função (FERRARI, 1997). Complementando esse entendimento, D'Agostini e Cunha (2007, p. 55) esclarecem que a noção de sistema implica atribuir significados às relações e aos elementos que se inter-relacionam.

Por sua vez, a literatura mais diretamente relacionada à vitalidade baseia-se em argumentos não apenas atrelados ao espaço, vinculando-se aos estudos da qualidade urbana, e discutindo o conceito ao menos sob dois aspectos: (1) como uma ação, ou seja, o ato de animar, de dar vida; (2) como um estado, significando a intensidade da vida social e de suas manifestações. O debate em torno dessas duas possibilidades define indicadores que dão uma ideia ampla sobre as formas de utilização efetiva dos espaços livres públicos, analisando a influência de sua configuração física na presença (ou não) de pessoas no local.

Assim, a vitalidade pode ser entendida como uma condição do espaço público, com características específicas (e que são alvo dessa investigação) as quais permitem atrair e manter em sua área, de usuários distintos (faixa etária, gênero, condição social, estado civil, escolaridade etc.), em variados horários e dias, realizando as mais diversas atividades.

De acordo com Holanda (2002), o uso dos espaços livres públicos remete à noção de presença de pessoas, ignorando inicialmente as atividades desenvolvidas por elas ou a duração de sua permanência. Essa ideia também é entendida como copresença que, conforme Goffman (1966), manifesta-se na percepção dos indivíduos de que estão suficientemente próximos de outros para: (1) serem percebidos no que quer que estejam fazendo, incluindo a sua experiência com os outros; (2) que a consciência de que se estão sendo percebidos pelo outro seja, ela mesma, perceptível. A presença de pessoas nos espaços livres públicos é considerada fundamental para a existência de um estado de vitalidade, tor- 
nando-se tema recorrente de autores como Jacobs (2001), Alexander et al. (1977), Whyte (1980) e Gehl (2006).

Constata-se haver uma riqueza de proposições que incidem sobre a vitalidade de praças, tratando-a desde sua concepção enquanto conceito até as múltiplas maneiras de potencializá-la nos espaços públicos urbanos. Dentre todos os elementos descritos, indicamos os seguintes como aqueles mais incisivos a essa pesquisa:

\section{Aspectos relativos à vitalidade urbana:}

- Copresença de pessoas em diferentes horários do dia;

- Realização de múltiplas atividades de permanência e de passagem.

- b. Aspectos relativos ao espaço e a seu entorno:

- Mobiliário e equipamentos urbanos que possibilitem o desenvolvimento de múltiplas atividades;

- Arborização e paisagismo como elementos naturais do espaço;

- Limpeza e conservação do ambiente e de seus elementos;

- Espaços para se sentar variados e bem posicionados;

- Entorno com uso residencial predominante, mas com a presença de atividades distintas de comércio e prestação de serviço;

- Existência de empreendimentos que incentivem o fluxo de pedestres no entorno - portos geradores de tráfego (PGTs);

- Diversidade no tempo de funcionamento dos imóveis não residenciais, possibilitando presença constante de indivíduos transitando no espaço público;
- Imóveis que se abrem para o espaço público através de várias aberturas, como portas e janelas;

- Presença de fronteiras suaves como zonas de transição entre o âmbito público e privado;

- Acessibilidade nas calçadas que levam ao ambiente.

\section{Metodologia}

A coleta de dados foi feita no âmbito dos estudos de caso, em que foram empregados: análise morfológica, observação sistematizada (mapeamento centrado no lugar) e registros fotográficos.

\subsection{Morfologia uRbana}

No âmbito da morfologia urbana, a coleta de dados ocorreu a partir de visitas in loco e consultas em mapas e documentos institucionais fornecidos pelos órgãos governamentais, imagens de satélite obtidas com o software Google Earth, e fotos aéreas. Tendo como base a literatura adotada, foram elencadas as variáveis à seguir (Quadro 1):

\subsection{Observações sistematizadas}

Nesta pesquisa, optou-se por realizar mapeamentos comportamentais (MP), que consistem em observações naturalísticas e sistemáticas do ambiente, registradas através de representações gráficas da ocupação humana em uma área, relacionando espaço físico (que precisa ser limitado e dividido em seções) e comportamento dos usuários (PINHEIRO; ELALI; FERNANDES, 2008). No trabalho realizado, os comportamentos observados foram registrados em uma ficha de observação, na qual os acontecimentos foram registrados às $10 \mathrm{~h}$, às $16 \mathrm{~h}$ e às $20 \mathrm{~h}$ e em dois dias diferentes da semana (terça e sábado), em duas semanas, durante o mês do outubro (Figura 1). 
Quadro 1 - Referências teórico-metodológicas da ANÁlise da VitAlidade urbana.

\begin{tabular}{|c|c|c|}
\hline ESCALA & VARIÁVEIS & O QUE AFERIR/QUAL AUTOR \\
\hline \multirow{4}{*}{$\begin{array}{l}\text { ENTORNO } \\
\text { IMEDIATO }\end{array}$} & Uso do solo & $\begin{array}{c}\text { Variedade de atividades (alimentação do equipamento) } \\
\text { Jacobs (2001), Gehl (2006), Whyte (1980) }\end{array}$ \\
\hline & Diversidade no turno de uso & Variedade de usuários Gehl (2006), Whyte (1980) \\
\hline & Fronteiras suaves & $\begin{array}{c}\text { Relação público x privado; presença de zonas de transição; atividades } \\
\text { existentes; e sensação de segurança Gehl (2006), Alexander et al. } \\
\text { (1977), Whyte (1980), Holanda (2002) }\end{array}$ \\
\hline & Portas e janelas & $\begin{array}{l}\text { Acessibilidade visual e sensação de segurança } \\
\text { Jacobs (2001), Whyte (1980), Gehl (2006), Holanda (2002) }\end{array}$ \\
\hline \multirow{3}{*}{ AMBIENTE } & Mobiliário e equipamentos & $\begin{array}{l}\text { 2Variedade de atividades e presença e variedade de usuários } \\
\text { Gehl (2006), Whyte (1980) }\end{array}$ \\
\hline & Paisagismo e Arborização & $\begin{array}{l}\text { Conforto ambiental; estética; e presença e variedade de usuários } \\
\text { Whyte (1980), Gehl (2002) }\end{array}$ \\
\hline & Espaços sentáveis & $\begin{array}{c}\text { Amenidades locais; presença; e variedade de usuários } \\
\text { Whyte (1980), Gehl (2002) }\end{array}$ \\
\hline
\end{tabular}

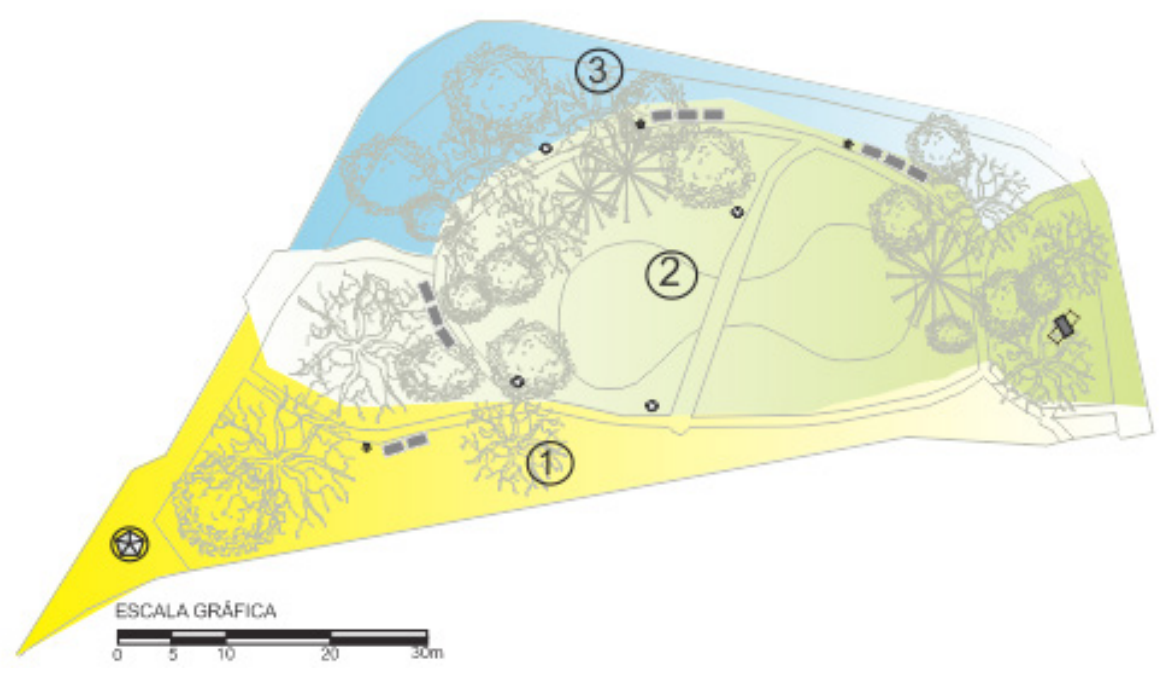

Figura 1 - Planta-baixa esquemática com a demarcação dos setores para das observações sistematizadas. 


\section{Morfologia e percepção dos usuários no Jardim Carrilho Videira}

A cidade do Porto, em Portugal, apresenta uma ampla diversidade de espaços livres públicos que se distribuem de maneira variada por todas as freguesias, refletindo a relação existente entre seus habitantes e a natureza ao longo do tempo.

Inicialmente relacionados a claustros, terreiros e pela proximidade a edifícios históricos, os jardins históricos, tidos como precursores do sistema de espaços livres públicos, funcionavam como principais ambientes abertos e recebiam os mais relevantes acontecimentos de lazer público do Porto. Posteriormente, com a expansão além das muralhas, surgem as quintas de recreio e as alamedas, e no final do século XIX ressalta-se a acentuada multiplicação de jardins privados e públicos, quando, além do Jardim de São Lazaro, a população passou a desfrutar também dos Jardins do Palácio de Cristal e da Cordoaria. O início do século XIX é contemplado com a inserção de novos padrões de estética e funcionalidade que procuraram enfatizar um ambiente romântico, conforme se vislumbrou nos seus primeiros jardins públicos.

O século XX é marcado por numerosos planos de ordenamento (como o Plano Regulador da Cidade do Porto de 1952 e o Plano Diretor da Cidade de Robert Auzelle em 1962) e a passagem de alguns espaços para a propriedade pública, enriquecendo a vida pública na cidade (MARTINS, 1992). Nesse momento, ressaltam-se alguns pontos em relação ao verde urbano: a redução na quantidade; seu deslocamento para a periferia; e o surgimento de novas tipologias de espaços de lazer, tais como as assembleias, clubes, ginásios e, posteriormente, os cinemas, que contribuíram para o afastamento das pessoas da esfera pública portuense.

Nas três décadas subsequentes, a implantação de áreas verdes foi sendo gradualmente reduzida e as ações públicas refletiam apenas em obras de ajardinamento aos pequenos espaços. O Plano Geral de Urbanização de Duarte Castel-Branco (de 1987) privilegia o desenvolvimento do turismo e do tecido sociocultural de cariz local, refletindo na melhora dos espaços públicos de lazer, especialmente daqueles que serviam como suporte para as ativi- dades turísticas. Atualmente, as proposições urbanísticas elaboradas para a cidade estão direcionados para o conteúdo urbanístico dos espaços verdes enquanto cinturões verdes ou como cortinas protetoras de embelezamento de espaços de fruição de lazer.

A dinâmica das intervenções urbanísticas propostas e as mudanças nos modos de vida levam a uma valorização de espaços de lazer históricos, que conservam uma configuração espacial de outros tempos, conservando uma estética e modos distintos de vivenciar a estrutura verde urbana. Hoje em dia, mesmo em número menor, ainda se observa a implantação de novos jardins públicos, embora, de acordo com Andresen e Marques (2001), tal fato não seja suficiente para fazer face às necessidades ambientais e paisagísticas da população urbana do século XXI do Porto.

Diante disso, Andresen e Marques (2001) referem-se à implantação do jardins do Carregal, Passeio Alegre, Arca d'Água e da Praça da República, que, na virada do século XIX, são construídos adaptando-se aos condicionantes topográficos e de limitações de área, seguindo os ideais românticos vigentes.

O jardim do Carregal (Jardim Carrilho Videira), anteriormente nomeado como Praça do Duque de Beja está localizado entre a Rua Dr. Tiago de Almeida e a Rua de Clemente Menéres, na freguesia de Miragaia, próximo ao Hospital Santo Antonio. Com o projeto de Jeronymo Monteiro da Costa, foi construído em 1897 em terreno cedido pela Santa Casa de Misericórdia à Câmara Municipal do Porto, contudo, só posteriormente passou por reformas e assumiu as feições atuais (Figura 2).

O jardim se organiza em torno de um lago de contornos irregulares, atravessado por uma ponte de pedra, sendo rodeado por grandes exemplares de coníferas, cedros e sequoias, plantados em canteiros entre caminhos sinuosos, refletindo um estilo naturalista de influência romântica, conforme gosto vigente na época de construção (Figura 3). O jardim possui 17 bancos, quatro postes de iluminação, um quiosque de venda de revistas e quatro lixeiras. 

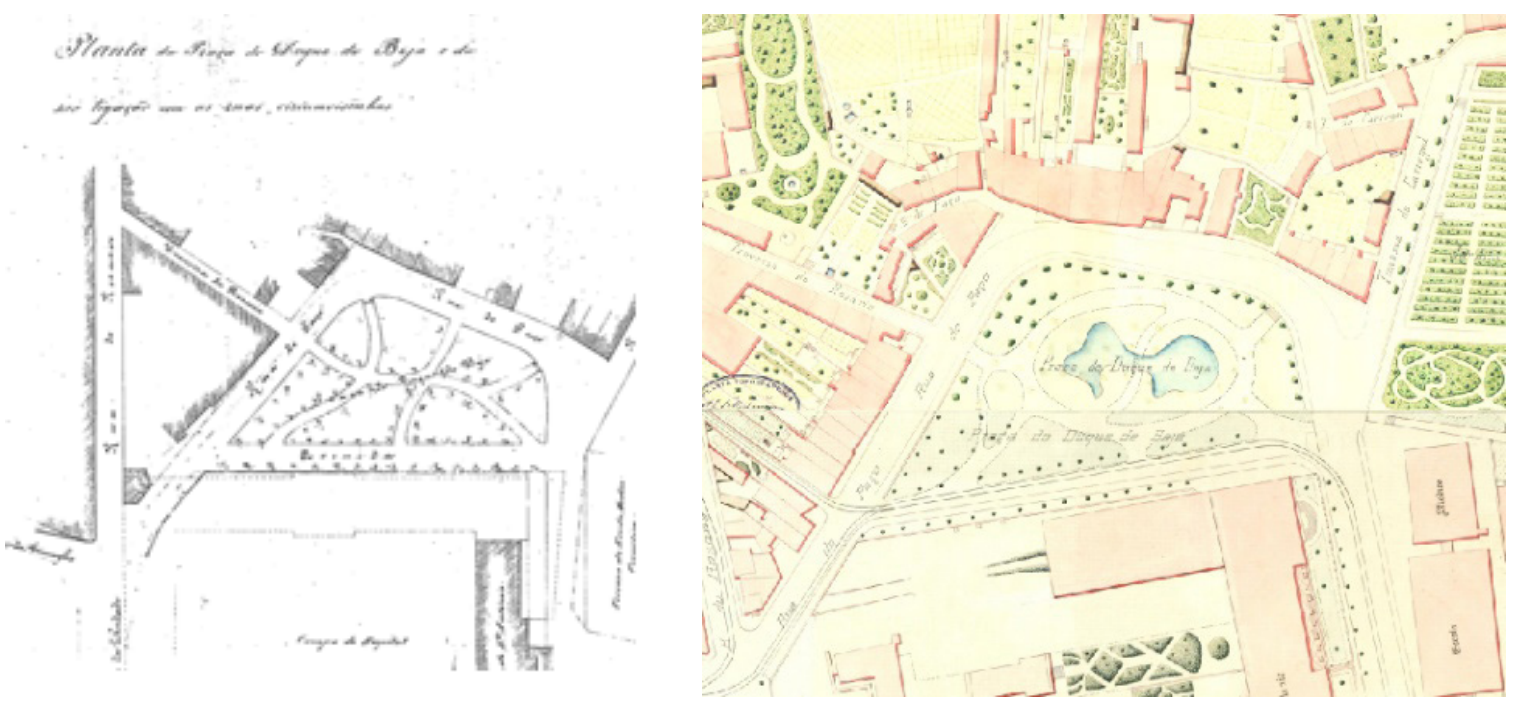

Figura 3 - Jardim Carrilho Videira, Porto, Portugal.

Fonte: Imagem aérea, Google Earth, editada pela autora. Fotos: Trícia Santana, 2018.
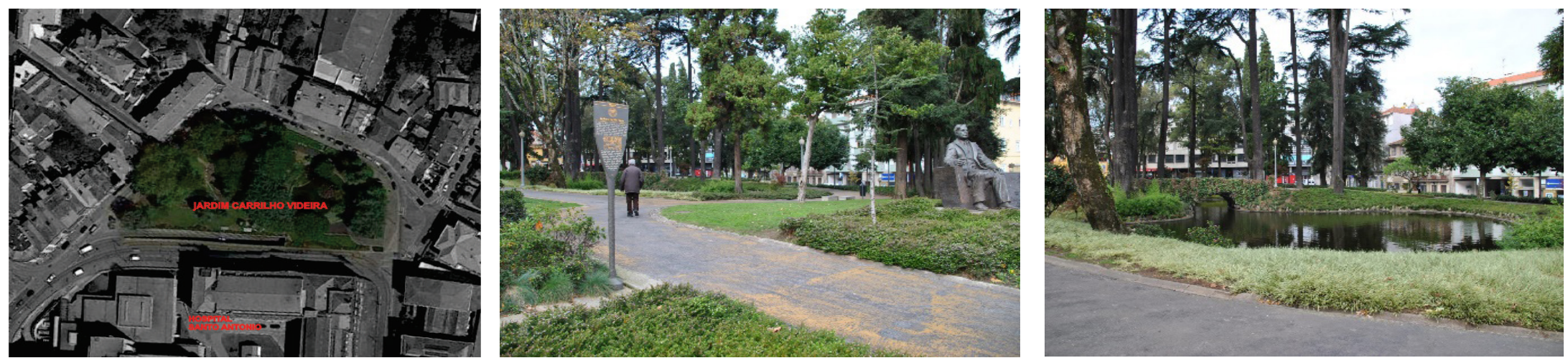

Figura 2 - Registros da Praça Duque de Beja.

Fonte: Arquivo Geral e Histórico da Câmara do Porto. 
Entendendo o jardim como um locus de sociabilidade, no qual o uso está relacionado tanto à configuração espacial existente quanto à percepção que os usuários têm do espaço, apresenta-se as análises morfoespaciais e comportamentais realizadas, enfatizando a discussão acerca dos pontos relacionados à vitalidade urbana, embasada na literatura de referência.

\subsection{Análise morfológica}

Neste item, são discutidos os pontos relacionados à morfologia urbana, entendendo-se que eles apresentam uma parcela na influência de utilização do lugar. São listados os itens relacionados ao entorno imediato e ao jardim em si.

\subsubsection{ENTORNO IMEDIATO}

\section{A. Uso do solo}

O uso do solo no entorno imediato da praça é amplamente diverso, com atividades distintas, das quais se sobressaem com maior quantidade aquelas relacionadas a atividades residenciais e de uso opcional (como o Hospital Geral Santo Antônio e o Instituto de Medicina Legal). Optou-se por trabalhar com uma análise do uso do solo que refletisse a copresença relacionada às maneiras como as pessoas visitam tais espaços, assim, os usos ficaram nomeados da seguinte maneira: residencial; cotidiano (padarias e escolas, por exemplo); eventual (como restaurantes e pequenos mercados); opcional (podendo ser drogaria e livraria); além do uso vazio/estacionamento. Nesse caso, as atividades de uso opcional estão em maior número $(43,24 \%)$, seguido pelo uso residencial $(27,02 \%)$. Nessa área, tem-se apenas um imóvel de uso cotidiano, trata-se de um pequeno mercado de venda de frutas (Figura 4).

É importante ressaltar, neste item, o papel do Hospital Santo Antônio como um polo gerador de tráfego (PGT) que contribui com fluxo de pessoas que circulam no entorno, ou passando propriamente pela área da praça. A existência desse PGT mostra-se relevante para a vitalidade da praça. O referencial teórico adotado sugere que a existência de atividades de uso eventual (como ca-

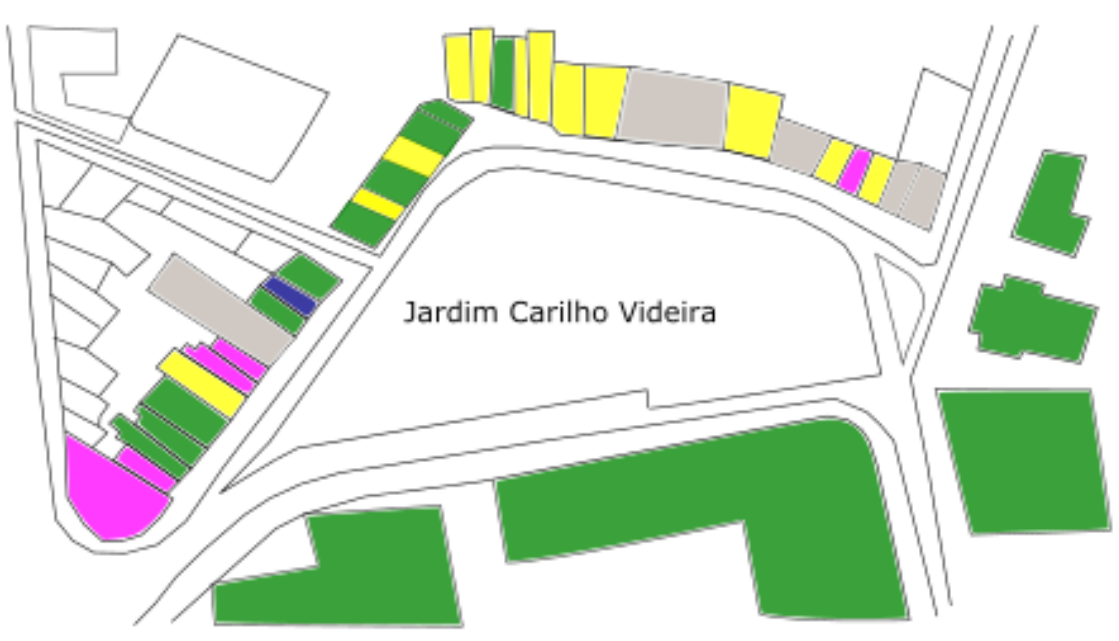

\section{LEGENDA}

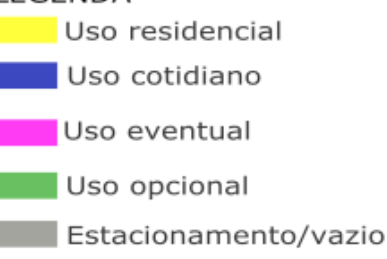

Figura 4 - Levantamento do uso do solo do entorno imediato. 
fés e restaurantes) e de PGTs concorrem para a copresença e são vistas como benéficas para a vitalidade da área. Essa variedade de atividades combinada com o uso residencial contribui para a ocorrência de veículos e pedestres trafegando nas proximidades da praça em diversos horários do dia e auxilia na possibilidade de haver uma interação social entre as pessoas, além de ampliar a sensação de segurança dos indivíduos (WHYTE, 1980).

Com esse cenário onde existem usos cotidianos, eventuais e opcionais, entende-se que o entorno representa uma alta diversidade no uso do solo, sendo a condição favorável para a promoção da vitalidade na área.

Já a diversidade no uso do solo pode potencializar o movimento de pessoas trafegando pelo entorno, gerando maiores possibilidades do espaço ser apropriado (JACOBS, 2001; GEHL, 2006; WHYTE, 1980; ALEXANDER et al., 1977). Para tanto, é importante que usos não residenciais ocorram no pavimento térreo, haja presença de empreendimentos voltados às atividades como alimentação, e existam vitrines amplas e coloridas. Por outro lado,

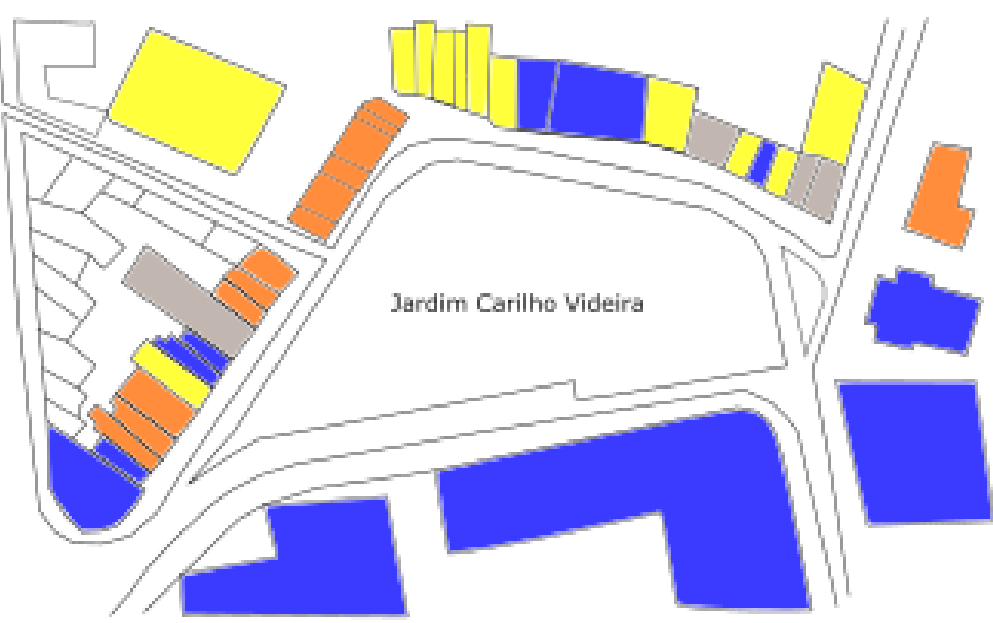

em algumas situações, a variedade do entorno pode ter mais relação com a atividade "estar de passagem", a qual, embora seja importante para a vitalidade urbana, não implica permanência (estadia prolongada), e também é importante analisar a presença de instituições hermeticamente vedadas ou autossuficientes, cuja relação com o entorno pode ser reduzida.

\section{b. Diversidade no turno de uso}

Os levantamentos realizados mostram que existe uma diversidade no turno do tempo favorável à vitalidade, já que existem imóveis que acolhem atividades que funcionam em dois (categoria II - 29,72\%) e em três períodos (categoria III - 29,72\%) e que, combinados com o uso residencial (computados em $29,72 \%$ ), possibilitam que o tráfego de pessoas ocorra em variados horários (Figura 5).

Essa complementaridade nos horários de funcionamento dos espaços comerciais é benéfica para a vitalidade da área, já que possibilita o movimento de pessoas nos três períodos dia, am-
LEGENDA

\footnotetext{
Uso residencial

Categoria I: uso em 1 periodo do dia

Categoria II: Uso em 2 períodos do dia

Categoria III: Uso em 3 períodos do dia

Vazio ou ruína
} 
pliando as chances de visitação da praça e ampliando a sensação de segurança na área. Segundo a categorização adotada, é uma área com diversidade alta no turno de uso, condição bastante favorável à vitalidade.

\section{Presença de fronteiras suaves}

A análise deste item foi baseada nas características das fachadas dos imóveis, objetivando visualizar a presença ou ausência de espaços que atuem como fronteiras suaves, que nesse caso estavam refletidos em usos como mesas de cafés e restaurantes ou venda nas calçadas, por exemplo.

Nas observações realizadas, foram registrados sete imóveis com fronteiras suaves $(18,91 \%)$, relativos aos edifícios que fazem uso do espaço público como uma extensão de seu negócio, como os cafés, o restaurante e a frutaria. Nota-se que essas fronteiras suaves estão dispersas no entorno imediato da praça em quadras distintas, influenciando no movimento de pessoas. A existência de calçadas largas (aproximadamente $6 \mathrm{~m}$ ), pavimentadas e pla- ocorre principalmente nos trechos voltados para rua Clemente Méneres (Figura 6).

Com essa configuração, a presença de fronteiras suaves é pouco favorável à vitalidade (presença de até $33 \%$ dos imóveis com fronteiras suaves), o que pode interferir na vitalidade na área.

\section{Presença de portas e janelas}

Verificou-se que a maior parte dos imóveis que abrem para o espaço público por portas e janelas (Categoria IV) ou por portas ou portões (Categoria III), que favorecem a comunicação entre aqueles que estão dentro e fora dos edifícios. Apenas um imóvel foi computado como muro cego (Hospital Santo Antonio). A maioria dos edifícios de categoria IV está localizada na Rua Clemente Menéres. Mesmo os imóveis residenciais existentes dispõem de portas e janelas que se voltam para o espaço público, facilitando essa relação entre o âmbito público e o privado, possibilitando a comunicabilidade entre as pessoas e ampliando as chances de uso do ambiente (Figura 7).

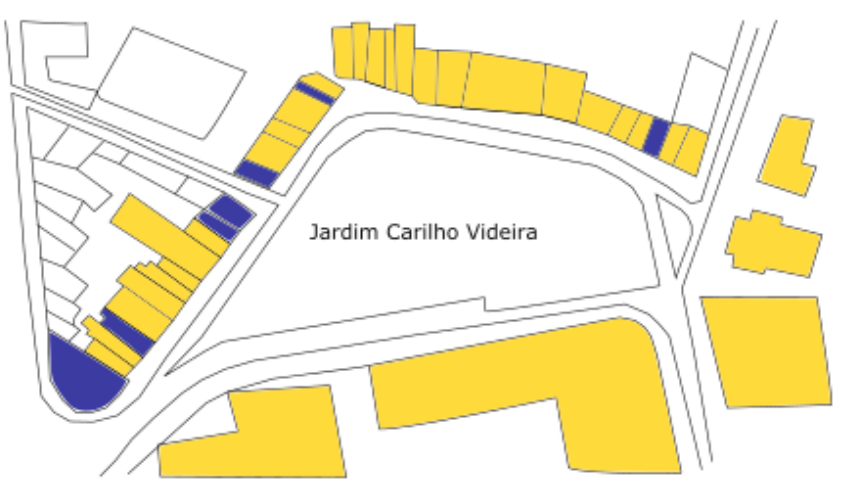

LEGENDA

Presença de Fronteira Suave Ausência de Fronteira Suave

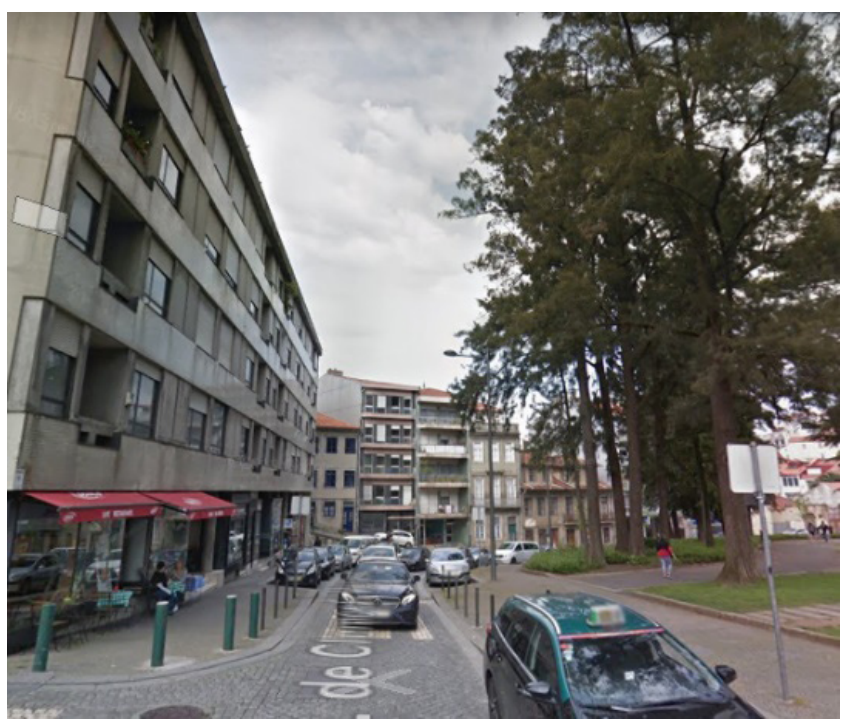

Figura 6: levantamento físico do item "fronteiras suaves". 
Essa situação foi considerada favorável à vitalidade o item "portas e janelas", aumentando a sensação de segurança, já que permite a comunicação entre o espaço público e o privado e possibilita o ato de vigilância e assistência voluntária entre os indivíduos.

\subsubsection{Escala do AMBiente}

Nesse subitem foram averiguadas as propriedades relacionadas ao ambiente em si, entendendo que elas podem influenciar a utilização do espaço. Foram elas: (1) itens do mobiliário e equi- pamentos urbanos; (2) vegetação: com itens da arborização e do paisagismo; e (3) espaços sentáveis.

\section{A. Itens do mobiliário e equipamentos urbanos}

Os itens que fazem parte da praça foram avaliados quanto à qualidade com que se apresentam. Assim viu-se que os bancos, a banca de revista, a escultura, as lixeiras e postes de iluminação estão em bom estado, limpos e conservados, mas possuem pouca diversidade, o que leva à escala de gradação de qualidade mediana, condição razoavelmente favorável à vitalidade (Figura 8).
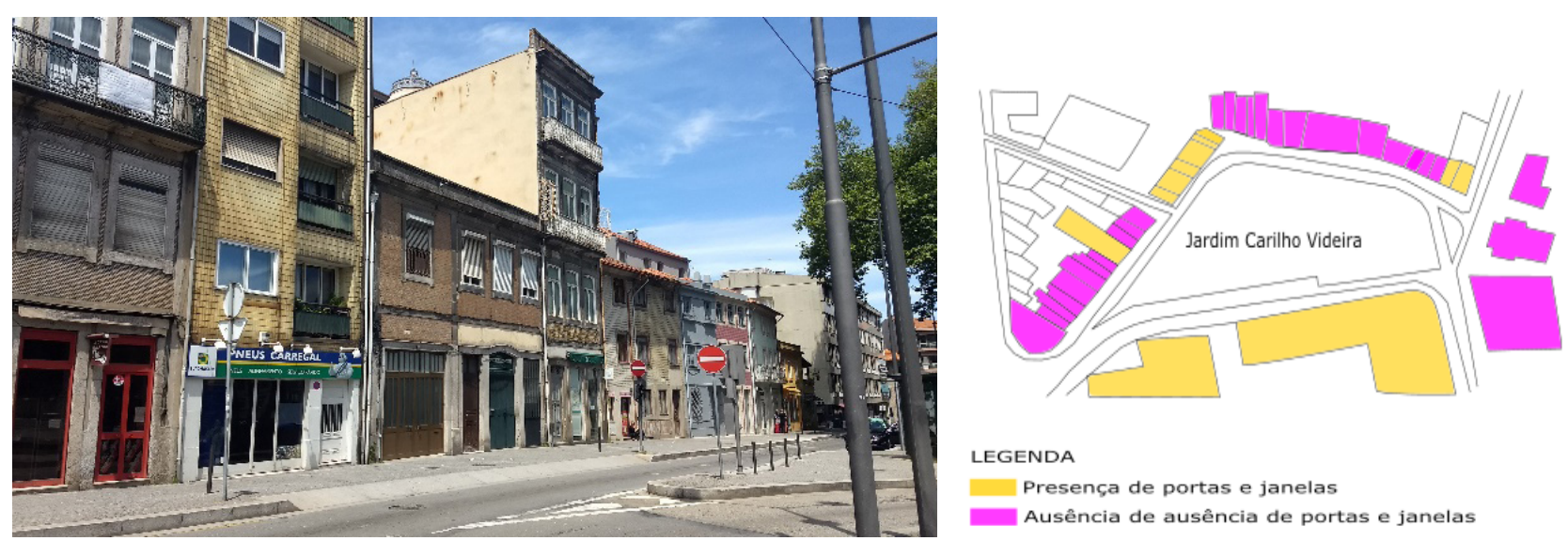

Figura 7: levantamento físico do item "Portas e janelas".
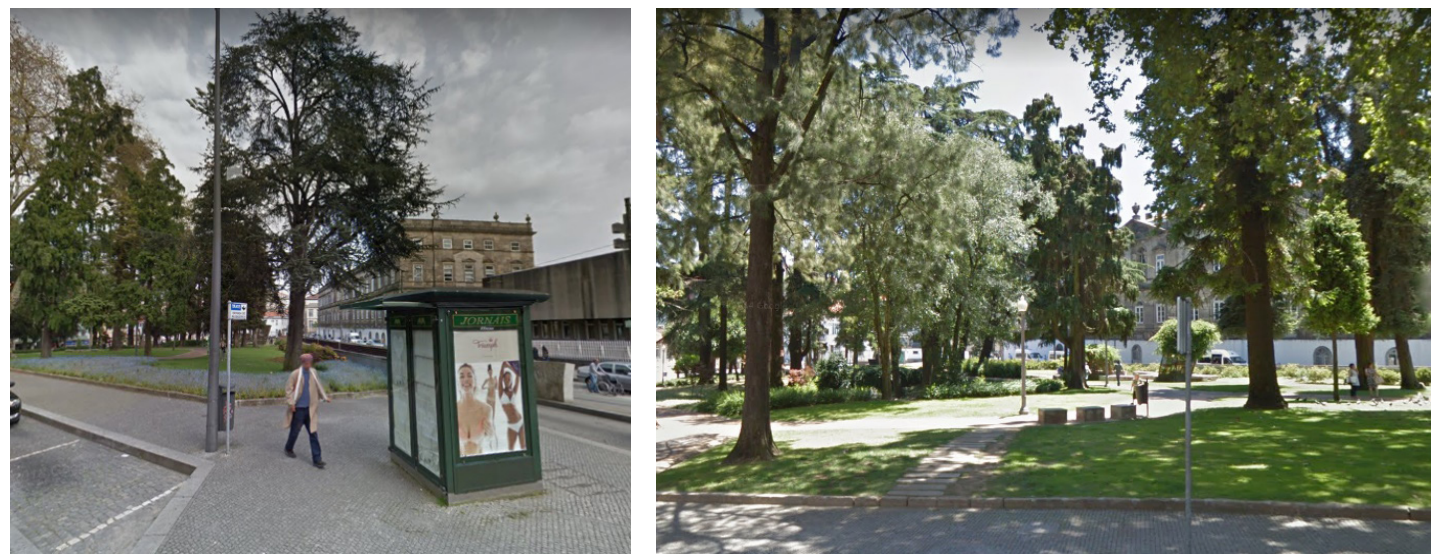

Figura 8 - Levantamento físico do item mobiliário e equipamentos urbanos. 


\section{B. Arborização e paisagismo}

A presença/ausência da natureza também é citada pela literatura como fator relevante para a ocupação do espaço urbano, com ênfase para seus efeitos para a saúde humana - influenciando desde a fisiologia dos sentidos até o bem-estar psicológico dos indivíduos (CARR et al., 1992; CHAUÍ, 1994; COOPER-MARCUS; FRANCIS, 1990; SERPA, 2007; WHYTE, 1980). Embora a presença de natureza seja um tema amplo (ao qual deveria corresponder o contato com diversos elementos, como, entre outros, ar puro, presença de água, vegetais e vida animal), considerando que o espaço público deveria possibilitar a seus usuários usufruir de momentos agradáveis e proteção de inclemências, a literatura ressalta o conforto em termos climáticos, enfocando mais especificamente a arborização e os elementos compositivos dos canteiros.

O jardim apresenta árvores de médio e grande porte que se distribuem formando uma grande sombra com as copas se tocando, formando um dossel natural, que cobre significativamente a maior área do lugar. Esse conjunto arbóreo é composto especialmente por cedros, sequoias e coníferas, que se localizam tanto na borda quanto no centro do lugar. Existe uma área na qual alguns bancos e caminhos não ficam situados sob a grande sombra arbórea, propiciando ao usuário oportunidades distintas no uso do espaço.

Já o paisagismo é apresentado sob a forma de exemplares arbustivos e herbáceos distribuídos por canteiros ao nível da forração gramada e com contornos irregulares. Tanto o paisagismo quanto o conjunto arbóreo apresentam-se em bom estado de conservação.

O lago irregular que ornamenta o centro do jardim é cruzado por uma ponte que se insinua como ruína, oferece ao usuário o contato visual com a água, que, em conjunto com a vegetação, pode propiciar conforto ambiental em momentos de elevada temperatura solar ou redução da umidade do ar (Figura 9).

Com essa configuração, composta por espécimes vegetais imponentes e componentes paisagísticos que enriquecem a experi-

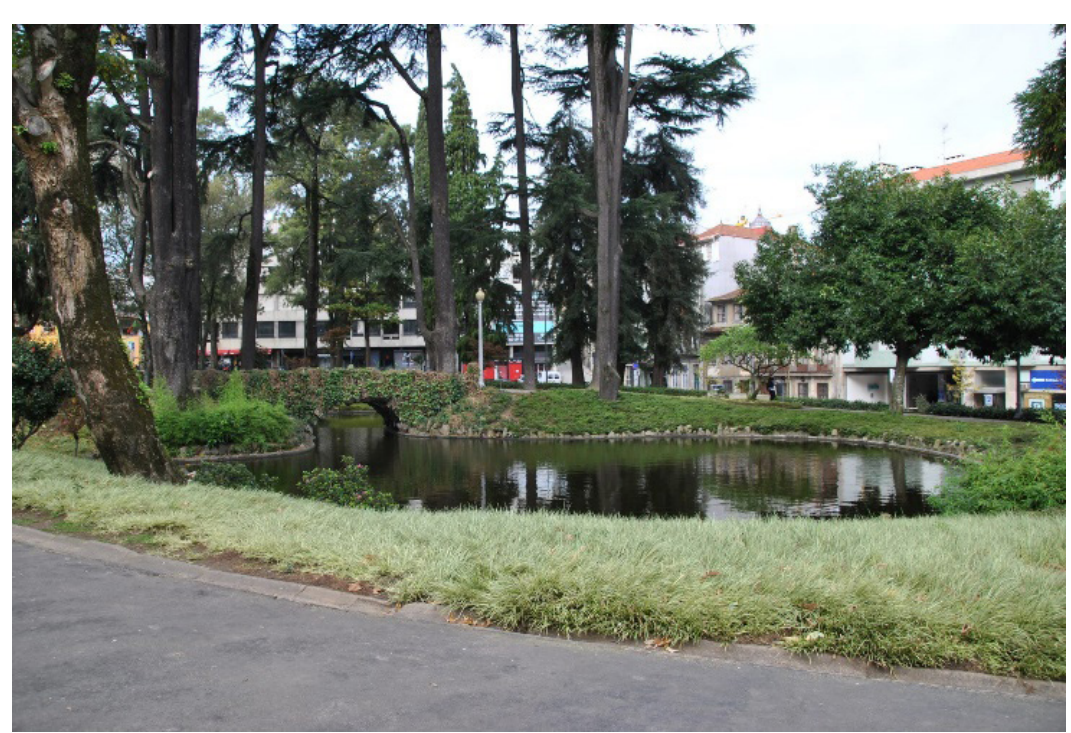

Figura 9 - Elementos de paisagismo e arborização.

ência do usuário, como o lago e a ponte, tem-se uma situação favorável à vitalidade do espaço.

\section{Elementos sentáveis}

Observou-se que no jardim apenas a escada se apresenta como um local informal para sentar, existem bancos (17 unidades) que se apresentam sob blocos retangulares de concreto e se espaIham nas bordas dos caminhos pavimentados. Nas proximidades da ponte, situa-se um conjunto de blocos de concreto que fazem às vezes de banco, considerados nesta pesquisa como elementos sentáveis informais. Tendo em vista tal configuração e segundo a bibliografia de referência, esses elementos sentáveis, formais e informais, distribuídos de maneira uniforme pelo jardim, são benéficos para a vitalidade urbana.

Considerando-se todos os itens morfológicos investigados (indicados pela literatura), seria razoável inferir que, quanto maior for a quantidade de elementos avaliados como favoráveis ao uso 


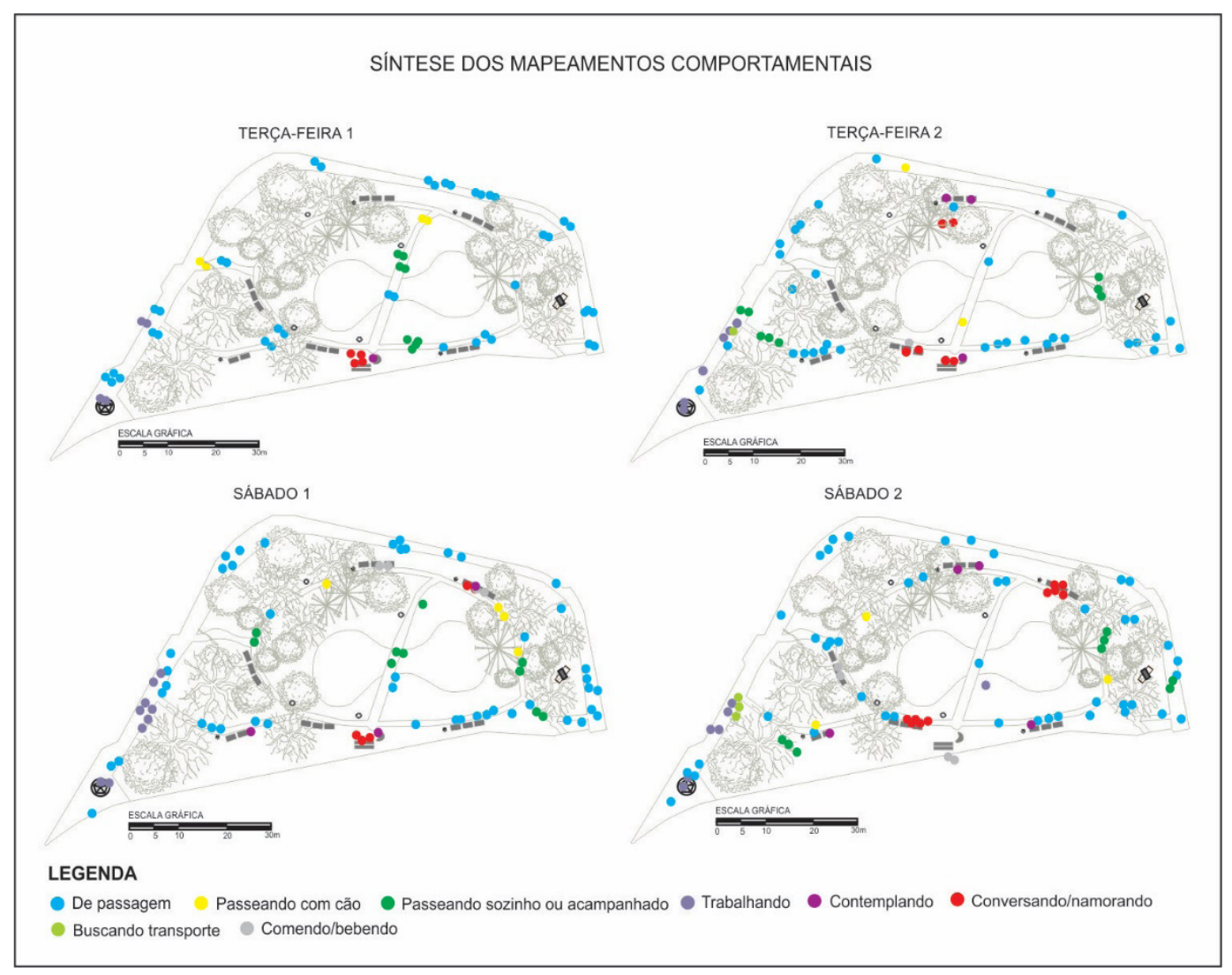

Figura 10 - Síntese dos mapeamentos comportamentais.

do local, maior a possibilidade dele ser efetivamente usado e, portanto, também seria maior a probabilidade de haver vitalidade, entendida como a presença de pessoas desempenhando múltiplas atividades (notadamente de permanência) em diferentes horários do dia (ALEXANDER et al., 1977; GEHL, 2006; WHYTE, 1980).

Com base nesse raciocínio, o Jardim do Carrilho Videira apresentou na sua análise morfológica todos os aspectos favoráveis à vitalidade, sugerindo um potencial de atrair usuários para funções de permanência em sua área. Essa qualidade morfológica pode ser justificada por sua localização, próxima ao centro histórico e comercial do Porto, em uma área turística, ao lado de um importante PGT (Hospital Santo Antonio). Justifica-se ainda pelo estado de conservação e manutenção do jardim e do entorno, que possibilita a permanência dos usuários. Além disso, ressalta-se a existência de um entorno que mescla atividades residenciais e de uso comercial e de prestação de serviços, possibilitando a circulação de uma ampla gama de pessoas pelo entorno e pelo jardim.

\subsubsection{AnÁlise comportamental}

Com os mapeamentos comportamentais, percebeu-se que a utilização espacial variou a cada dia e hora, bem como a ocorrência de atividades. No total, foram computadas 292 pessoas em todos os momentos observados. As atividades registradas foram: passear com cães (PC); passear com pessoas (PP); contemplar (CT); namorar/conversar (NC); comer/beber (CB); trabalhar (TR); estar de passagem (DP) e buscar transporte (BT). A seguir, há a síntese dos dias de observação (Figura 10). 
O dia de maior visitação foi o segundo sábado, com 86 pessoas, e a primeira terça-feira foi o dia que recebeu menos usuários, 60. Em todos os momentos, a atividade "estar de passagem" foi a mais registrada, com 169 indivíduos, sendo mais expressiva nos horários das $10 \mathrm{~h}$ e $16 \mathrm{~h}$, de todos os dias observados. Algumas atividades são marcantes em determinados locais, nesse sentido, pela existência de uma paragem de táxis (setor 1), a atividade "buscar transporte" foi registrada, em menor quantidade, com 4 usuários computados em todos os dias. Quanto às atividades consideradas de permanência, "conversar/namorar", "passear com pessoas" e "trabalhar" foram as mais registradas (Tabela 1).

Nota-se que o setor de maior uso foi o de número 1 em todos os dias e horários (total de 146 pessoas), exceto na primeira terçafeira. Nesse setor se tem um caminho pouco sinuoso que cruza o jardim em sua maior extensão e possibilita que se caminhe de um lado ao outro por um percurso sombreado e visualmente agradável, com a possibilidade de sentar-se. Trata-se de uma zona interessante que acolheu diversas atividades, apoiadas especialmente pelos seus espaços para se sentar, como "contemplar", "comer/ beber", "conversar/namorar", oferecendo uma visão do lago, da ponte e do restante do jardim.

Já no setor 2 está localizado o lago na parte central do jardim, um importante atrativo, com bancos que possibilitam o acesso visual à toda a área e aos canteiros floridos que a decoram. Esse setor recebeu atividades diversificadas, tais como: "conversar/ namorar", "passear com pessoas", "comer/beber", " passear com cão".

O setor 3 abrange principalmente o percurso que transita pelo anel externo do jardim, levando o usuário a caminhar por um nível abaixo do restante da área e próximo ao estacionamento do jardim e do entorno. Entende-se que caminham por ele os usuários que não fazem questão de transitar pelo jardim em si, mas buscam outros atrativos do entorno.

Quanto aos horários de maior visitação, tem-se que o período noturno foi aquele que menos registraram-se usuários em todos os dias de observações (75), especialmente na terça-feira (12).
Tabela 1 - Mapeamentos comportamentais CENTRADOS NO LUGAR.

\begin{tabular}{|c|c|c|c|c|c|c|c|c|c|c|}
\hline \multirow{2}{*}{ DIA } & \multirow{2}{*}{ SETOR } & \multicolumn{8}{|c|}{ ATIVIDADES } & \multirow{2}{*}{ TOTAL } \\
\hline & & DP & TR & PC & PP & CB & CT & NC & BT & \\
\hline \multirow{4}{*}{ 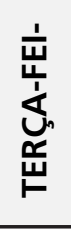 } & 1 & 17 & 4 & 0 & 2 & 0 & 1 & 0 & 0 & 24 \\
\hline & 2 & 16 & 0 & 4 & 4 & 0 & 0 & 2 & 0 & 26 \\
\hline & 3 & 10 & 0 & 0 & 0 & 0 & 0 & 0 & 0 & 10 \\
\hline & TOTAL & 43 & 4 & 4 & 6 & 0 & 1 & 2 & 0 & 60 \\
\hline \multirow{4}{*}{ 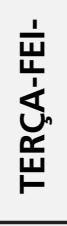 } & 1 & 18 & 6 & 0 & 5 & 1 & 1 & 5 & 1 & 37 \\
\hline & 2 & 7 & 0 & 1 & 3 & 0 & 2 & 2 & 0 & 15 \\
\hline & 3 & 9 & 0 & 2 & 0 & 0 & 0 & 0 & 0 & 11 \\
\hline & TOTAL & 34 & 6 & 3 & 8 & 1 & 3 & 7 & 1 & 63 \\
\hline \multirow{4}{*}{ 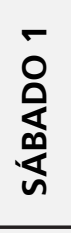 } & 1 & 22 & 9 & 0 & 2 & 0 & 2 & 6 & 0 & 41 \\
\hline & 2 & 11 & 0 & 4 & 8 & 4 & 1 & 2 & 0 & 30 \\
\hline & 3 & 12 & 0 & 0 & 0 & 0 & 0 & 0 & 0 & 12 \\
\hline & TOTAL & 45 & 9 & 4 & 10 & 4 & 3 & 8 & 0 & 83 \\
\hline \multirow{4}{*}{ 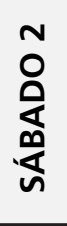 } & 1 & 21 & 7 & 1 & 3 & 2 & 2 & 5 & 3 & 44 \\
\hline & 2 & 16 & 0 & 2 & 5 & 2 & 2 & 5 & 0 & 32 \\
\hline & 3 & 10 & 0 & 0 & 0 & 0 & 0 & 0 & 0 & 10 \\
\hline & TOTAL & 47 & 7 & 3 & 8 & 4 & 4 & 10 & 3 & 86 \\
\hline \multicolumn{2}{|c|}{ TOTAL } & & 26 & 14 & 32 & 9 & 11 & 27 & 4 & 292 \\
\hline
\end{tabular}

Nesse período, a atividade "estar de passagem" foi a mais registrada (42), seguida de "passear com pessoas" (11) e "conversar/ namorar" (13) (Tabela 2).

Em termos de uso, o tipo de ocupação observado mostrou uma tendência à realização de atividades diretamente relacionadas às possibilidades existentes no lugar, o que também influenciará no 
Tabela 2 - Mapeamentos comportamentais CENTRADOS NO LUGAR.

\begin{tabular}{|c|c|c|c|c|c|c|c|c|c|c|}
\hline & \multirow{2}{*}{ HORA } & \multicolumn{8}{|c|}{ ATIVIDADES } & \multirow{2}{*}{ TOTAL } \\
\hline & & DP & TR & PC & PP & CB & CT & NC & BT & \\
\hline \multirow{4}{*}{ 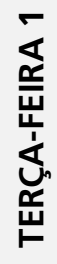 } & $10 \mathrm{H}$ & 21 & 2 & 2 & 2 & 0 & 1 & 0 & 0 & 28 \\
\hline & $16 \mathrm{H}$ & 13 & 2 & 1 & 2 & 0 & 0 & 2 & 0 & 20 \\
\hline & $20 \mathrm{H}$ & 9 & 0 & 1 & 2 & 0 & 0 & 0 & 0 & 12 \\
\hline & TOTAL & 43 & 4 & 4 & 6 & 0 & 1 & 2 & 0 & 60 \\
\hline \multirow{4}{*}{ 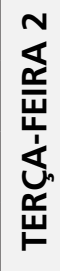 } & $10 \mathrm{H}$ & 12 & 3 & 1 & 3 & 1 & 1 & 3 & 0 & 24 \\
\hline & $16 \mathrm{H}$ & 12 & 2 & 1 & 3 & 0 & 1 & 2 & 1 & 22 \\
\hline & $20 \mathrm{H}$ & 10 & 1 & 1 & 2 & 0 & 1 & 2 & 0 & 17 \\
\hline & TOTAL & 34 & 6 & 3 & 8 & 1 & 3 & 7 & 1 & 63 \\
\hline \multirow{4}{*}{ 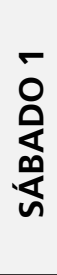 } & $10 \mathrm{H}$ & 15 & 3 & 2 & 2 & 0 & 0 & 5 & 0 & 27 \\
\hline & $16 \mathrm{H}$ & 19 & 4 & 1 & 4 & 2 & 2 & 0 & 0 & 32 \\
\hline & $20 \mathrm{H}$ & 11 & 2 & 1 & 4 & 2 & 1 & 3 & 0 & 24 \\
\hline & TOTAL & 45 & 9 & 4 & 10 & 4 & 3 & 8 & 0 & 83 \\
\hline \multirow{4}{*}{ 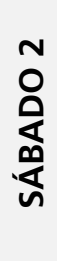 } & $10 \mathrm{H}$ & 19 & 4 & 1 & 3 & 2 & 2 & 2 & 0 & 33 \\
\hline & $16 \mathrm{H}$ & 16 & 3 & 1 & 2 & 2 & 1 & 3 & 3 & 31 \\
\hline & $20 \mathrm{H}$ & 12 & 0 & 1 & 3 & 0 & 1 & 5 & 0 & 22 \\
\hline & TOTAL & 47 & 7 & 3 & 8 & 4 & 4 & 10 & 3 & 86 \\
\hline
\end{tabular}

público (crianças, adultos, jovens). Embora a pesquisa não tenha tecido diferenças entre gênero e idade dos usuários, nota-se que atividades como brincar/jogar e fazer exercícios, por exemplo, não são muito frequentes, haja vista que não existem brinquedos infantis ou outros equipamentos que possibilitem essas práticas. Por outro lado, mesmo não havendo quiosques de venda de comida e bebida, ainda assim foram registradas pessoas realizando essas tarefas, contudo, isso pode ocorrer em função da existência de cafés e restaurantes no entorno, o que ilustra a relação do lugar com o contexto espacial em que ele está inserido. Esse quadro geral corrobora com a literatura (GEHL, 2006; LIBERALINO 2011; SILVA, 2014), sobretudo no que diz respeito à relação entre a morfologia e o desenvolvimento de atividades de grupos específicos, como ilustram situações de conversa ou contemplação (bancos confortáveis), brincadeiras (playground) e prática esportiva ou de exercícios (quadra, academia de terceira idade, calçada plana e bem conservada).

Investigando ainda o uso do espaço, nota-se a quantidade máxima de usuários simultâneos é muito próxima em todos os momentos de observação (primeira terça-feira: 60 pessoas; segunda terça-feira: 63 pessoas; primeiro sábado: 80 pessoas; segundo sábado: 83 pessoas) e, em função disso, a densidade máxima obtida é diferente em cada caso, o que nos leva a pensar quais atributos investigados estão influenciando mais fortemente esse uso, e na possibilidade de outros elementos também estarem atuando no local para que a vitalidade ocorra e se sustente.

Um primeiro aspecto a comentar nesse sentido é a dimensão dos espaços. Em termos lineares, Gehl (2006) defende que um espaço público não deve ultrapassar $100 \mathrm{~m}$. Por outro lado, Whyte (1980) indica que, se o lugar não for excessivamente grande, suas dimensões não serão um problema para a interação entre os indivíduos. No caso investigado, o jardim possui uma de suas dimensões acima desse valor (lado maior: $155 m$ - Rua Dr. Tiago de Almeida), o que não aparenta alterar suas condições de uso quer sob o ponto de vista dos usuários, quer pelo mapeamento comportamental (que não mostrou diferenças significativas de ocupação entre suas partes e o perímetro). Portanto, se ambientes menores favorecem a interação social entre os usuários e, consequentemente, oferecem melhores possibilidades de vitalidade, realmente o jardim tem vantagem nesse item. 
A percepção da arborização e sua valorização pela população tem reflexo nos horários de uso e nos locais mais utilizados. Assim, a manhã e a tarde representam os momentos com maior quantidade de público. Pondera-se que outras questões (sociais, de estilo de vida, por exemplo) também podem interferir no horário de visitação dos lugares, mas as condições de conforto parecem ter sua parcela de influência nesse aspecto.

Quanto aos elementos compositivos do espaço, entende-se que propostas que possibilitem a contemplação, o contato com a natureza e a interação social também influenciam a percepção dos usuários, mas atuam menos sobre suas escolhas, não chegando ao ponto, por exemplo, de restringir o uso do lugar.

\section{Considerações Finais}

Em uma espécie de analogia à vitalidade humana, a vitalidade de um espaço foi entendida como elemento indispensável à saúde e à vida da cidade, como uma linha intermediária entre a apatia e a excitação. Trata-se, portanto, da capacidade de animação em função das relações sociais que acontecem em um lugar, sendo condicionada pelos atributos morfológicos do ambiente, mas também pela percepção que seus usuários têm dele. Supõese, assim, que existe um tipo de vitalidade desejável para cada tipo de espaço, isso é, que uma área comercial exige um tipo de animação diferente daquela necessária a um setor residencial, embora alguns dos elementos/atributos dessa vitalidade possam ser válidos para ambos.

O desenvolvimento da pesquisa apontou a importância dos espaços públicos das cidades serem pensados a partir de um olhar atento para particularidades morfoespacial e socioculturais dos diferentes lugares, e valorizando a percepção dos usuários. A literatura clássica na área conduziu à compreensão de que a vitalidade urbana é um tema rico quanto à quantidade de aspectos que devem ser considerados e inter-relacionados, que encontram ressonância em pesquisas empíricas recentes. Assim, partindo de uma matriz de critérios para avaliação do desempenho do Jardim Carrilho Videira, na cidade do Porto, esse estudo tentou agregar abordagens morfológicas e perceptivas a fim de entender o uso do ambiente público.

Em relação ao entorno, ressalta-se, ainda, que os aspectos da morfologia investigadas não levaram em conta algumas características de seu entorno (como a topografia, por exemplo), apontando para a necessidade de futuras análises abordarem outros aspectos, entre os quais se destacam: como a densidade populacional da área próxima afeta a densidade de uso dos espaços ali existentes? A tipologia edilícia da área lindeira interfere na diversidade de atividades desenvolvidas no lugar e na densidade de sua utilização? A posição do jardim em relação ao nível do solo do entorno influencia sua apropriação? Como a situação socioeconômica da população se reflete na utilização dos espaços públicos de um bairro?

Pelas atividades desenvolvidas no lugar, percebe-se que a influência da morfologia espacial - do ambiente em si mais do que de seu entorno - afeta a intensidade e a frequência com que os comportamentos ocorrem, em especial no desenvolvimento de atividades opcionais e sociais, bem como participa nas escolhas e percepções dos indivíduos, levando-os a reproduzir uma relação de identidade muito próxima com as oportunidade de uso do lugar.

Devido ao caráter multidimensional e interdependente que envolve os processos de identificação e utilização dos ambientes públicos, seria essencial investigar como outros fatores, de cunho econômico, social e cultural, concorrem para influenciar a percepção dos indivíduos e suas relações com os espaços cotidianos, os quais não foram investigados nesta tese (revelando-se uma limitação dessa pesquisa), mas se configuram como sugestão para outros estudos que aprofundem o debate. Outros pontos que poderão orientar novas investigações são: análise da situação socioeconômica da área e dos habitantes do entorno dos espaços; realização de mapeamento comportamental centrado na pessoa a fim de verificar detalhes do uso do espaço; pesquisa da percepção ambiental dos trabalhadores do entorno, buscando uma perspectiva diferenciada sobre o uso da área; e ampliação da análise morfoespacial. 
Entendemos que trabalhar uma abordagem morfológica sob a ótica dos usuários é mais uma maneira de entender o fenômeno da vitalidade nos espaços livres públicos, valorizando a percepção dos moradores e visitantes enquanto indivíduos capazes de opinar na constituição de seus espaços cotidianos, servindo como importante referencial para qualquer intervenção que neles venha a acontecer.

\section{REFERÊNCIAS BiBLIOGRÁFICAS}

ALEXANDER, Christopher; ISHIKAWA, Sara; SILVERSTEIN, Murray; JACOBSON, Max; FIKS DAHL-KING, Ingrid; ANGEL, Shlomo. A pattern language: towns, buildings, construction. Nova York: Oxford University Press, 1977.

ANDRESEN, Teresa; MARQUES, Teresa Portela. Jardins Históricos do Porto. Lisboa: Inapa, 2001

ARENDT, Hannah. A condição humana. Rio de Janeiro: Forense Universitária, 1991.

CALDEIRA, Teresa Pires do Rio. Cidade de muros: crime, segregação e cidadania em São Paulo. São Paulo: Editora 34: Edusp, 2000.

CARR, Stephen; FRANCIS, Mark; RIVLIN, Leanne G.; STONE, Andrew M. Public space New York: Cambridge University Press, 1992. Disponível em: https://books.google com. br/books? id=pjo4AAAAIAAJ\&printsec =frontcover \&dq=Carr+Public+Places\&hl=p $\mathrm{t}-\mathrm{BR} \& \mathrm{sa}=X \& \mathrm{i}=082 \mathrm{iVLwDwteDBlyMhMAO} \& \mathrm{ved}=0 \mathrm{CB} 4 \mathrm{Q} 6 \mathrm{AEwAA \# v}=$ onepage $\& \mathrm{q}=\mathrm{Carr} \% 20$ Public\%20Places\&f=false Acesso em: 21 abr. 2019

CHAUÍ, Marilena. Convite à filosofia. São Paulo: Ática, 1994.

COOPER MARCUS, Clare; FRANCIS, Carolyn (ed.). People places: design guidelines for urban open space. New York: Van Nostrand Reinhold, 1990.

D'AGOSTINI, Luiz Renato; CUNHA, Ana Paula Pereira. Ambiente. Rio de Janeiro: Garamond, 2007

FERRARI, Célson. Planejamento municipal integrado. São Paulo: Pioneira, 1997.

GEHL, Jan. La humanización del espacio urbano: la vida social entre los edificios. Barcelona: Reverté, 2006.

GEHL, Jan; GEMZØE, Lars. Novos espaços urbanos. São Paulo: Gustavo Gilli, 2002.

GOFFMAN, Erving. Behavior in public places. New York: Free Press, 1966.

GOMES, Paulo César da Costa. A condição urbana: ensaios de geopolítica da cidade. Rio de Janeiro: Bertrand Brasil, 2002.

HABERMAS, Jürgen. Mudança estrutural da esfera pública: investigações quanto a uma categoria da sociedade burguesa. Rio de Janeiro: Tempo Brasileiro, 1984.

HALL, Edward T. A dimensão oculta. Rio de Janeiro: Francisco Alves, 1977.

HOLANDA, Frederico Rosa Borges de. O espaço de exceção. Brasília, DF: Editora UnB, 2002.
HOLANDA, Frederico Rosa Borges de. A determinação negativa do movimento moderno. In: HOLANDA, Frederico Rosa Borges de (org.). Arquitetura e Urbanidade. 2. ed. Brasília, DF: FRBH Edições, 2011. p. 19-37.

JACOBS, Jane. Morte e vida de grandes cidades. São Paulo: Martins Fontes, 2001.

JODELET, Denise. A cidade e a memória. In: DEL RIO, Vicente; DUARTE, Crisitiane Rose RHEINGANTZ, Paulo Afonso. Projeto do Lugar: colaboração entre psicologia, arquitetura e urbanismo. Rio de Janeiro: Contra Capa, 2002. p. 31-43.

LIBERALINO, Cintia Camila. Praça: lugar de lazer: relações entre características ambientais e comportamentais na Praça Kalina Maia - Natal RN. 2011. Dissertação (Mestrado em Psicologia) - Universidade Federal do Rio Grande do Norte, Natal, 2011

MARTINS, Luis Paulo Saldanha. Do passeio público ao "jogo de cartas": apontamentos sobre os espaços ajardinados do Porto. COLÓQUIO IBÉRICO DE GEOGRAFIA, 6., 1992, Porto. Anais [...]. Porto: Universidade do Porto, 1992. p. 627-640.

NETTO, Vinicius M. O efeito da arquitetura: Impactos sociais, econômicos e ambientais de diferentes configurações de quarteirão. Arquitextos, São Paulo, ano 7, n. 079.07, 2006. Disponível em: http://www.vitruvius.com.br/revistas/read/arquitextos/07.079/290. Acesso em: 21 abr. 2013.

PINHEIRO, José Q.; ELALI, Gleice A.; FERNANDES, Odara S. Observando a interação pessoa-ambiente: vestígios ambientais e mapeamento comportamental. In: PINHEIRO, José Q. GÜNTHER, Hartmut (org.). Métodos de pesquisa nos estudos pessoa-ambiente. São Paulo: Casa do Psicólogo, 2008. p. 75-104.

SENNETT, Richard. O declínio do homem público: as tiranias da intimidade. São Paulo: Companhia das Letras, 1988

SERPA, Angelo. O espaço público na cidade contemporânea. São Paulo: Contexto, 2007.

SILVA, Eduardo Alexandre Ribeiro da. Interação social e envelhecimento ativo: um estudo em duas praças de Natal/RN. Tese (Doutorado em Psicologia) - Programa de Pós-Graduação em Psicologia, Universidade Federal do Rio Grande do Norte, Natal, 2014.

TUAN, Yi-Fu. Espaço e lugar: a perspectiva da experiência. São Paulo: Difel, 1983.

YURGEL, Marlene. Urbanismo e lazer. São Paulo: Nobel, 1983.

WHYTE, William H. The social life of small urban spaces. New York: Project for Public Spaces, 1980 
Trícia Caroline da Silva Santana

Universidade Federal Rural do Semi-Árido (Ufersa).

Rua Baía das Canárias, 2234, Natal, RN, Brasil, CEP 59092-295

CV: http://lattes.cnpq.br/4315619665111241

Orcid: https://orcid.org/0000-0002-1415-4508

E-mail: triciasantana@gmail.com

\section{Graça Correia Ragazzi}

Universidade do Porto. Faculdade de Arquitectura (Faup)

R. de Augusto Rosa 24, 4000-098 Porto, Portugal

Orcid: http://orcid.org/0000-0003-2308-5425

E-mail: correiaragazzi@gmail.com

Nota do Editor:

Submetido em: 23/06/2019

Aprovado em: 10/07/2019

Revisão do texto: Tikinet 